\title{
On the Role of Ferromagnetic Interactions in Highly Active Mo-Based Catalysts for Ammonia Synthesis
}

\author{
Julen Munarriz, ${ }^{*[a]}$ Victor Polo, ${ }^{[a]}$ and Jose Gracia ${ }^{*[b]}$
}

\begin{abstract}
Reactions involving nitrogen fixation and transfer are of great industrial interest. In this regard, unveiling all the physical principles that determine their activity would be enormously beneficial for the rational design of novel catalysts with improved performance. Within this context, this work explores the activity of bulk molybdenum-based transition metal nitrides in ammonia synthesis. Our results highlight that the most active compositions show increasing ferromagnetism in the metalnitrogen bonds, which constitute the active sites. We observe that the total spin accumulated in the bonds at the active sites is a physically meaningful descriptor to discriminate optimum catalysts. Higher activities are associated with ferromagnetic phases, and the underlying reason is an enhanced overlapping of the electronic wavefunctions; which also make the reaction steps spin-sensitive. These finding provides strong evidence of the general influence of electrons magnetic moment in catalysis, being part of the specific field of spintro-catalysis.
\end{abstract}

Spin-dependent potentials are decisive for the kinetics of electron transfer reactions at magnetic interphases. ${ }^{[1,2]}$ Catalysts with preferential ferromagnetic (FM) exchange interactions are optimized on the basis of energy shells antisymmetric in space, $\psi_{\text {antisym, being distinguished as "spintro-catalysts". }{ }^{[3]} \text { The studies }}$ performed so far on magnetic catalysts have focused on oxygen electrochemistry, revealing the importance of quantum exchange interactions (QEI), ${ }^{[4-5]}$ as well as their implications for the understanding and developing of efficient energy technologies. However, the interest and applicability of novel concepts like FM enhanced covalent bonds, ${ }^{[3]}$ reduced Coulomb interactions ${ }^{[1]}$ and spin-sensitive reaction steps in compositions with $\psi_{\text {antisym }}$ is wider, and might be extended to other relevant chemical processes, as it is the case of nitrogen fixation to produce ammonia. ${ }^{[6]}$

The progressive fossil fuels depletion and the need for reducing environmental pollution has resulted in a growing interest to develop new renewable energetic processes, [7] looking for geopolitically stable alternatives. Within this context, ammonia plays a key role for the maintenance of a steady

\section{[a] J. Munarriz, Dr. V. Polo}

Departamento de Química Física and Instituto de

Biocomputación y Física de Sistemas Complejos (BIFI)

Universidad de Zaragoza, Zaragoza, Spain, 50009

E-mail: julen@unizar.es

[b] Dr. J. Gracia

Magnetocat SL

General Polavieja 9 3l, Alicante, Spain, 03012

E-mail: magnetocat@outlook.com sustainable economy, as it allows the clean synthesis of fertilizers, having also significant applications in the production of plastics, nitric acid and in fuel cells. ${ }^{[8,9]}$ On an industrial scale, ammonia is obtained almost exclusively via the reduction of nitrogen with hydrogen through the Haber Bosch process. This synthesis is expensive, requiring high temperatures and pressures, as well as very pure streams of gases. The reaction takes place over iron or ruthenium-based heterogeneous catalysts and requires about $485 \mathrm{~kJ} \mathrm{~mol}^{-1}$ overall. ${ }^{[10]}$ On the other hand, nitrogen fixation in nature is achieved under mild conditions via an enzymatic reaction catalyzed by the so called nitrogenases. Among them, FeMo-nitrogenases are reported to be the most active. ${ }^{[11,12]}$ On balance, the process requires $244 \mathrm{~kJ} \mathrm{~mol}^{-1}$, almost half than in industry. ${ }^{[13]}$ Researchers have tried to mimic this "natural" catalyst; what has resulted into stimulating advances, as the synthesis of efficient molybdenum $^{[14]}$ and iron-based ${ }^{[15,16]}$ complexes with high activity. Another relevant approach uses complex transition metal nitrides as heterogeneous catalysts; ${ }^{[17-19]}$ with activities for the ternary nitrides following the order $\mathrm{Co}_{3} \mathrm{Mo}_{3} \mathrm{~N}_{1-\delta}>\mathrm{Fe}_{3} \mathrm{Mo}_{3} \mathrm{~N}_{1-\delta}>$ $\mathrm{Ni}_{2} \mathrm{Mo}_{3} \mathrm{~N}_{1-\delta .} \cdot{ }^{[17,18]}$ Both, experimental results and ab-initio calculations, show that the number of nitrogen vacancies present on $\mathrm{Co}_{3} \mathrm{Mo}_{3} \mathrm{~N}$-based materials can adsorb and activate the strong $\mathrm{N} \equiv \mathrm{N}$ triple bond. ${ }^{[20,21]}$ As a result, some authors have proposed that nitrogen fixation occurs via a Mars-van Krevelen (MvK) mechanism, as shown in Scheme $1 .{ }^{[22,23]}$ However, the influence

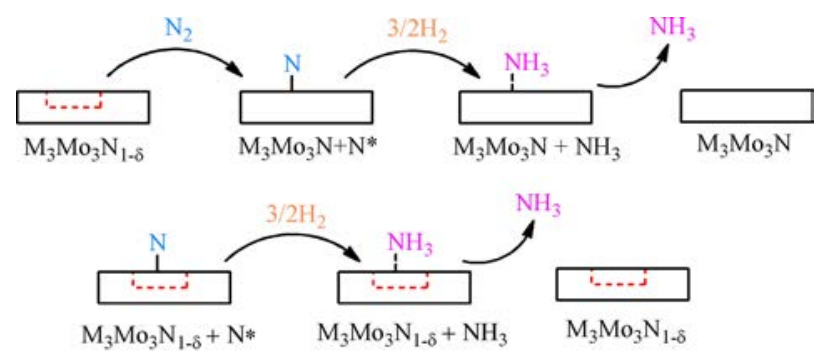

$$
\begin{aligned}
& \mathrm{M}_{3} \mathrm{Mo}_{3} \mathrm{~N}_{1-\delta}+\mathrm{N}_{2} \rightarrow \mathrm{M}_{3} \mathrm{Mo}_{3} \mathrm{~N}+\mathrm{N}^{*} \\
& \mathrm{M}_{3} \mathrm{Mo}_{3} \mathrm{~N}+\mathrm{N}^{*}+3 / 2 \mathrm{H}_{2} \rightarrow \mathrm{M}_{3} \mathrm{Mo}_{3} \mathrm{~N}+\mathrm{NH}_{3} ; \\
& \mathrm{M}_{3} \mathrm{Mo}_{3} \mathrm{~N} \rightarrow \mathrm{M}_{3} \mathrm{Mo}_{3} \mathrm{~N}_{1-\delta}+\mathrm{N}^{*} \\
& \mathrm{M}_{3} \mathrm{Mo}_{3} \mathrm{~N}_{1-\delta}+\mathrm{N}^{*}+3 / 2 \mathrm{H}_{2} \rightarrow \mathrm{M}_{3} \mathrm{Mo}_{3} \mathrm{~N}_{1-\delta}+\mathrm{NH}_{3} \\
& \mathrm{M}_{3} \mathrm{Mo}_{3} \mathrm{~N}_{1-\delta}+\mathrm{N}_{2}+3 \mathrm{H}_{2} \rightarrow \mathrm{M}_{3} \mathrm{Mo}_{3} \mathrm{~N}_{1-\delta}+2 \mathrm{NH}_{3}
\end{aligned}
$$

Scheme 1. Schematic representation of Mars-van Krevelen mechanism for ammonia synthesis on $\mathrm{M}_{3} \mathrm{Mo}_{3} \mathrm{~N}_{1-\delta}$ catalysts. 
of the electronic and magnetic structure of Mo-based transition metal nitrides in their catalytic activity have barely been explored.

Transition metal oxides with preferential FM spin delocalization are excellent catalysts for oxygen electrochemistry. ${ }^{[1,6,24]}$ The explanation lies on the fact that augmented QEI in spinpolarized conductors assists the electron transfer and spin selection. ${ }^{[1,5]}$ In addition, oxygen vacancies are also a crucial part of their reaction mechanisms. ${ }^{[25]}$ Within this context, we aim to apply the same physical principles that work for oxygen electrochemistry to understand the importance of spin exchange potentials in nitrogen hydrogenation. For that, we have theoretically studied the magnetic structure of the related $\mathrm{FeCO}_{2} \mathrm{Mo}_{3} \mathrm{~N}_{1-\delta}, \mathrm{Co}_{3} \mathrm{Mo}_{3} \mathrm{~N}_{1-\delta}, \mathrm{Fe}_{3} \mathrm{Mo}_{3} \mathrm{~N}_{1-\delta}$ and $\mathrm{Ni}_{2} \mathrm{Mo}_{3} \mathrm{~N}_{1-\delta}$ catalysts, see Figure 1, focusing on the orbital physics responsible of their activity. The principles presented herein should be general for catalytic $\mathrm{N}_{2}$ activation and can be used for the "rational design" of optimum compositions. ${ }^{[26]}$

The magnetic structure of the nitrides was studied by means of periodic DFT calculations. Fe and Co-based nitrides were found to present a FM metallic ground state (G.S.) ${ }^{[27,28]}$ while $\mathrm{Ni}_{2} \mathrm{Mo}_{3} \mathrm{~N}$ is nonmagnetic, as reported by other authors. ${ }^{[29,30]}$ These kind of compositions are also active for oxygen reduction; ${ }^{[3]}$ and nitrogen fixation has similarities with $\mathrm{O}_{2}$ reduction as the double bond in oxygen molecule must be activated by incoming electrons in a similar way as the triple bond of nitrogen molecule. In both cases, electrons are to be incorporated into $\pi^{*}$ molecular orbitals prior to the immobilization of protons. It is also known that FM potentials reduce the influence of the Coulomb interactions, and intermediates overall present a reaction mechanism with optimum activation energies for electron transfer in oxygen electrochemistry. ${ }^{[1]}$ In this regard, one of the fingerprints in spintro-catalysis is the general reduction of the free activation energies by a quantity that is proportional to the FM spin-moment of the active sites. Within this correlation, we have used the Heisenberg Hamiltonian to quantify the QEl; that is: $H_{\mathrm{QEI}}=\triangle \mathrm{J}_{\mathrm{QEI}} \cdot S_{\text {cat }}$ where, $\triangle \mathrm{J}_{\mathrm{QEI}}$ is a catalytic exchange coupling constant and $\boldsymbol{S}_{\text {cat }}$ is the average spin moment at the active sites. ${ }^{[31]}$

We start the analysis from nitrogen defective unit cells, as the active catalysts present nitrogen vacancies at reaction conditions. ${ }^{[25]}$ For that, we subtracted one of the sixteen nitrogen atoms in the unit cell of $\mathrm{Fe}_{3} \mathrm{Mo}_{3} \mathrm{~N}, \mathrm{Co}_{3} \mathrm{Mo}_{3} \mathrm{~N}$ and $\mathrm{FeCO}_{2} \mathrm{Mo}_{3} \mathrm{~N}_{\text {, }}^{[32]}$ as well as in an equivalent (with respect to the number of nitrogen atoms) $\mathrm{Ni}_{2} \mathrm{Mo}_{3} \mathrm{~N}$ supercell $(2 \times 2 \times 1) ;{ }^{[33]}$ thus making stoichiometries of the form $\mathrm{M}_{\mathrm{x}} \mathrm{Mo}_{3} \mathrm{~N}_{0.94}$. As shown in Table 1, all the structures, but slightly antiferromagnetic (AFM)
(a) $\mathrm{Fe}_{3} \mathrm{Mo}_{3} \mathrm{~N}_{1-\delta}$
(b) $\mathrm{Co}_{3} \mathrm{Mo}_{3} \mathrm{~N}_{1-\delta}$

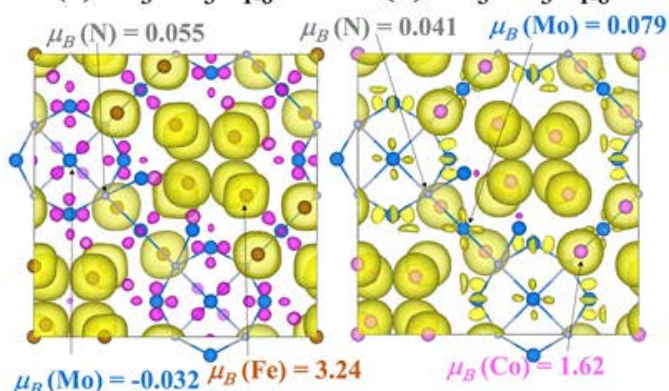

$\mu_{B}(\mathrm{Mo})=-0.032 \mu_{B}(\mathrm{Fe})=3.24$
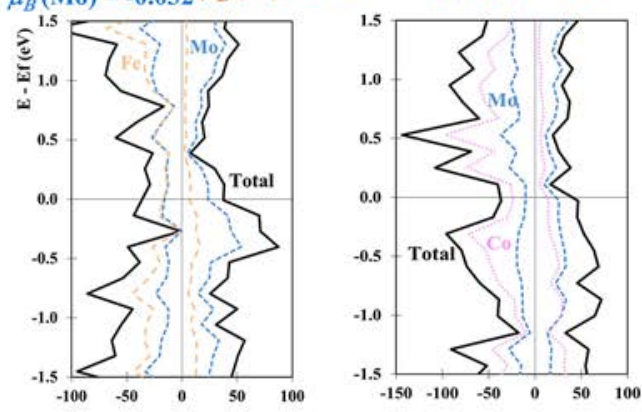

(c) $\mathrm{FeCo}_{2} \mathrm{Mo}_{3} \mathrm{~N}_{1-\delta}$

(d) $\mathrm{Ni}_{2} \mathrm{Mo}_{3} \mathrm{~N}_{1-\delta}$
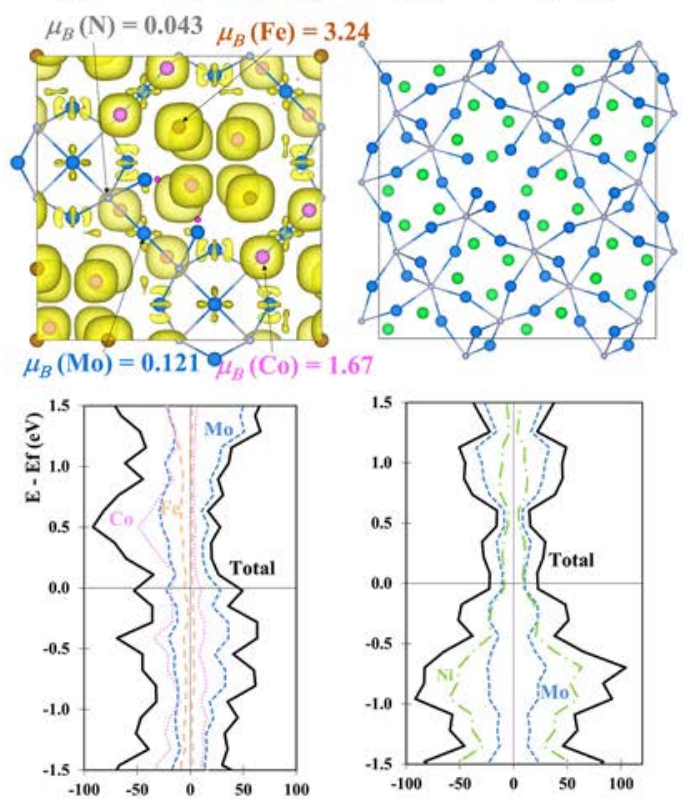

Figure 1. Spin density (yellow: up; purple: down; spin majority in the positive side, isovalue of $0.01 \mathrm{e}^{-} \AA^{-3}$ ), density of states, and magnetic moments (in a.u.) for the most stable magnetic phase of nitrogen defective: a) $\mathrm{Fe}_{3} \mathrm{Mo}_{3} \mathrm{~N}_{1-\delta \prime}$ b) $\mathrm{Co} 3 \mathrm{Mo} 3 \mathrm{~N}_{1-\delta}$, c) $\mathrm{FeCO}_{2} \mathrm{Mo}_{3} \mathrm{~N}_{1-\delta}$, and d) $\mathrm{Ni}_{2} \mathrm{Mo}_{3} \mathrm{~N}_{1-\delta}$.

\begin{tabular}{|c|c|c|c|c|c|c|c|}
\hline & $\begin{array}{l}\mathrm{N} \text { defective } \\
\text { FM-AFM }\end{array}$ & $E_{\mathrm{e}} / n_{\mathrm{e}-}$ & $d(\mathrm{Mo}-\mathrm{N})$ & $\begin{array}{l}\text { Non-N-defective } \\
\text { FM-AFM }\end{array}$ & $E_{\mathrm{e}} / n_{\mathrm{e}-}$ & $d(\mathrm{Mo}-\mathrm{N})$ & $\begin{array}{l}\text { Energy of formation } \\
\mathrm{N} \text { vacancies }\end{array}$ \\
\hline $\mathrm{FeCO}_{2} \mathrm{Mo}_{3} \mathrm{~N}_{1-\delta}$ & 86 & 0.864 & 2.083 & 89 & 0.870 & 2.081 & 54 \\
\hline $\mathrm{Co}_{3} \mathrm{Mo}_{3} \mathrm{~N}_{1-\delta}$ & 115 & 0.853 & 2.090 & 113 & 0.860 & 2.089 & 50 \\
\hline $\mathrm{Fe}_{3} \mathrm{Mo}_{3} \mathrm{~N}_{1-\delta}$ & 134 & 0.877 & 2.102 & 138 & 0.883 & 2.098 & 63 \\
\hline $\mathrm{Ni}_{2} \mathrm{Mo}_{3} \mathrm{~N}_{1-\delta}$ & - & 0.758 & 2.075 & - & 0.764 & 2.068 & 49 \\
\hline
\end{tabular}


$\mathrm{Ni}_{2} \mathrm{Mo}_{3} \mathrm{~N}_{0.94}$, have FM G.S.; and they keep the same magnetic structure as the fully stoichiometric compounds, as will be explained later on in the text. In the bulk, Mo-N bonds represent the active centers for $\mathrm{N}_{2}$ hydrogenation, and, noteworthy, the overall increase in the magnetic moments on these bonds agrees with the enhanced catalytic activity (cf. Figure 1): $\mathrm{Ni}_{2} \mathrm{Mo}_{3} \mathrm{~N}_{1-\delta}\left(0.0 \mu_{B}\right)<\mathrm{Fe}_{3} \mathrm{Mo}_{3} \mathrm{~N}_{1-\delta}\left(0.023 \mu_{B}\right)<\mathrm{Co}_{3} \mathrm{Mo}_{3} \mathrm{~N}_{1-\delta}(0.120$ $\left.\mu_{B}\right)<\mathrm{FeCo}_{2} \mathrm{Mo}_{3} \mathrm{~N}_{1-\delta}\left(0.164 \mu_{B}\right)$; the maximum activity of the $\mathrm{FeCO}_{2} \mathrm{Mo}_{3} \mathrm{~N}_{1-\delta}$ structure results as a theoretical prediction of our study. To rationalize this correlation, consider $H_{Q E I}$ as a perturbation that reduces the energy of the system by an increment in the number of unpaired electrons. As a consequence, there is a change in the spatial symmetry that decreases Coulomb potentials and enhance covalent interactions. This way, ferromagnetism anticipates at least the possibility of lowering the activation barriers of the rate limiting step upon spin polarization.

For non-vacant systems, the spin polarization in the Mo-N bonds follows again the sequence: $\mathrm{Ni}_{2} \mathrm{Mo}_{3} \mathrm{~N}\left(0.0 \mu_{\mathrm{B}}\right)<\mathrm{Fe}_{3} \mathrm{Mo}_{3} \mathrm{~N}$ $\left(0.045 \mu_{\mathrm{B}}\right)<\mathrm{Co}_{3} \mathrm{Mo}_{3} \mathrm{~N}\left(0.123 \mu_{\mathrm{B}}\right)<\mathrm{FeCo}_{2} \mathrm{Mo}_{3} \mathrm{~N}\left(0.187 \mu_{\mathrm{B}}\right)$, see Figure 2 and Table 2 . The increment in the magnetic moment is due to the additional oxidation provided by the extra nitrogen atoms. FM holes located at the Mo-N bonds, in conjunction with the magnetization of these bonds, indicate the ability of the catalysts to polarize spin-density from the $2 p$-orbitals of the nitrogen atoms. In other words, the magnetic moment in the Mo-N bonds is an indication of the ability of the catalyst to overlap with the $2 p$-orbitals of the intermediate nitrogenates during $\mathrm{NH}_{3}$ synthesis.

In $\mathrm{Fe}_{3} \mathrm{Mo}_{3} \mathrm{~N}$, the iron's magnetic moment is $3.03 \mu_{\mathrm{B}}$, while the molybdenum atoms have a magnetic moment close to 0 , associated with the typical low spin (L.S.) states of $4 d$-Mo systems. ${ }^{[34]}$ The molybdenum magnetic moment, although small, presents the opposite orientation (negative sign) with respect to iron atoms, which prefer a FM orientation with respect to each other, see Table 2 . In the iron atoms, the strong intra-atomic FM exchange interactions in the $3 d$-orbitals polarize the electronic density, and since there are enough empty orbitals at the Fermi level, the inter-atomic exchange interactions between the polarized iron atoms become also FM. The iron atoms are the least electronegative of the $3 d$-metals and the bigger $4 d$-orbitals are only slightly polarized. $\mathrm{Ni}_{2} \mathrm{Mo}_{3} \mathrm{~N}_{1-\delta}$ and $\mathrm{Fe}_{3} \mathrm{Mo}_{3} \mathrm{~N}_{1-\delta}$ are the least active catalysts and result to be the compositions in which the Mo atoms have no spin-polarization or which are somewhat AFM with respect to the rest of the metallic atoms (in $\mathrm{Fe}_{3} \mathrm{Mo}_{3} \mathrm{~N}_{1-\delta}$ Fe atoms are $\mathrm{FM}$ with respect to themselves, but AFM with respect to slightly magnetic polarized Mo atoms). As a result, the Mo-N bond distances are longer, Fermi heaps, the formation energy of nitrogen vacancies is higher, the system is more rigid as shown by the highest FMAFM energy differences, and the $d$-metal orbitals participate less in the conduction band near the Fermi level. In $\mathrm{Co}_{3} \mathrm{Mo}_{3} \mathrm{~N}_{1-\delta}$ the cobalt cations present an average magnetic moment of $1.63 \mu_{\mathrm{B}}$, smaller than those of iron atoms, indicating that the antibonding $3 d$-band is more saturated. The cobalt $3 d$-orbitals spill-over the magnetic moment towards the Mo cations by oxidizing them, as indicated by the lower Bader atomic charge

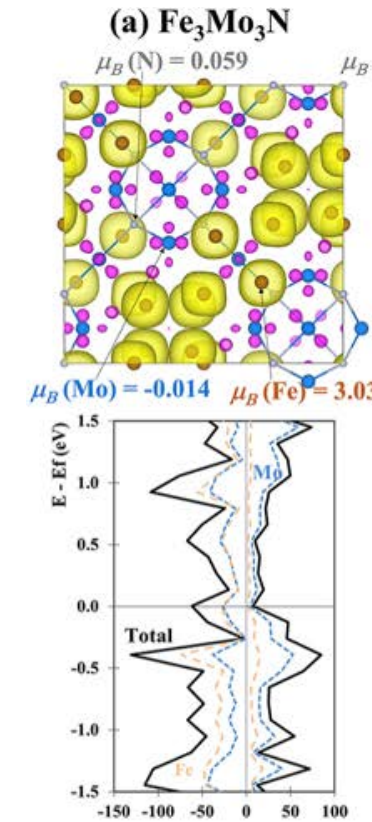

(b) $\mathrm{Co}_{3} \mathrm{Mo}_{3} \mathrm{~N}$

(c) $\mathrm{FeCo}_{2} \mathrm{Mo}_{3} \mathrm{~N}$
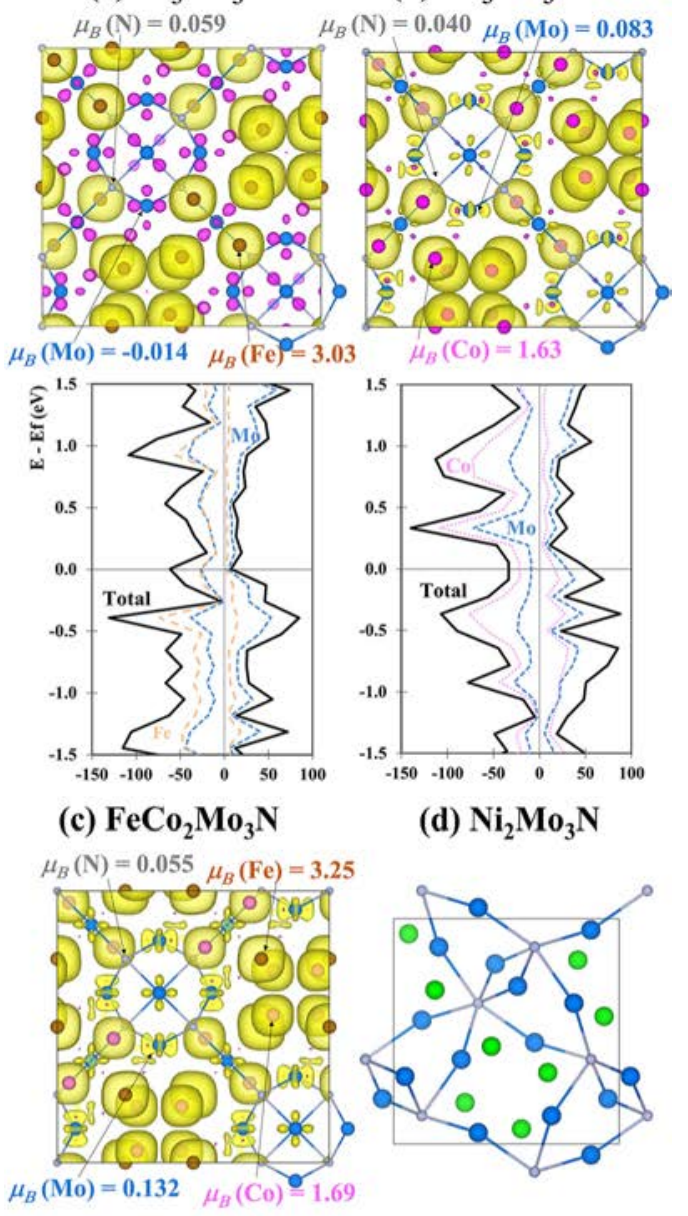

(d) $\mathrm{Ni}_{2} \mathrm{Mo}_{3} \mathrm{~N}$
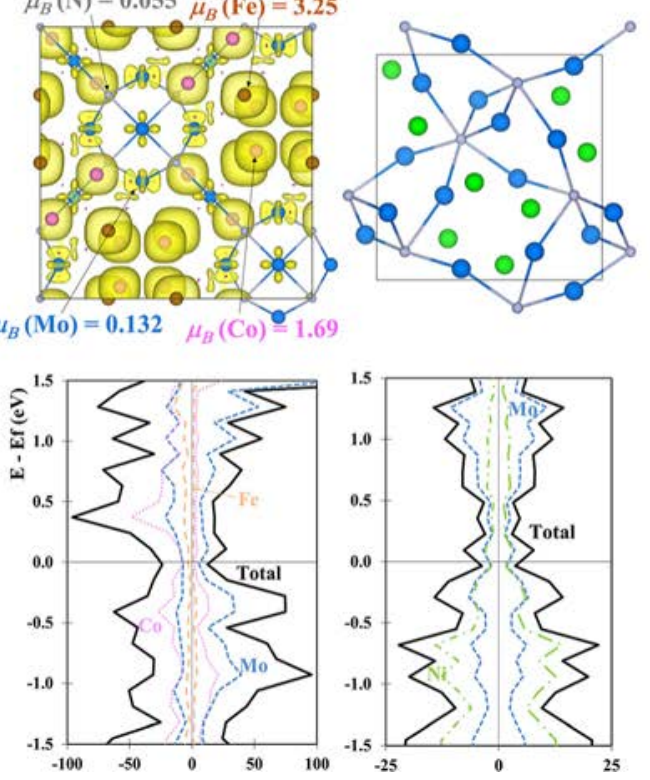

Figure 2. Spin density (yellow: up; purple: down; spin majority in the positive side, isovalue of $0.01 \mathrm{e}^{-} \AA^{-3}$ ), density of states, and magnetic moments (in a.u.) for the most stable magnetic phase of nitrogen defective: a) $\mathrm{Fe}_{3} \mathrm{Mo}_{3} \mathrm{~N}$, b) $\mathrm{Co} 3 \mathrm{Mo} 3 \mathrm{~N}, \mathrm{c}) \mathrm{FeCO}_{2} \mathrm{Mo}_{3} \mathrm{~N}$, and d) $\mathrm{Ni}_{2} \mathrm{Mo}_{3} \mathrm{~N}$.

of $\mathrm{Mo}$ in $\mathrm{Co}_{3} \mathrm{Mo}_{3} \mathrm{~N}_{1-\delta}$ with respect to $\mathrm{Fe}_{3} \mathrm{Mo}_{3} \mathrm{~N}_{1-\delta}$, see Table 2; the magnetism accumulated in the Mo-N bonds in $\mathrm{Co}_{3} \mathrm{Mo}_{3} \mathrm{~N}_{1-\delta}$ is about three times the values in $\mathrm{Fe}_{3} \mathrm{Mo}_{3} \mathrm{~N}_{1-\delta}$. In this case, as well as in $\mathrm{FeCO}_{2} \mathrm{Mo}_{3} \mathrm{~N}_{1-\delta}$, all atoms are in an overall $\mathrm{FM}$ state. In $\mathrm{FeCO}_{2} \mathrm{Mo}_{3} \mathrm{~N}_{1-\delta}$, the iron atoms present a magnetic moment of $3.25 \mu_{\mathrm{B}}$, while the value for cobalt ions is $1.69 \mu_{\mathrm{B}}$; the spin polarization of the Mo-N bonds is significantly the greatest of the considered materials, as also shown by shortest bond distance, Fermi holes, see Table 2. There is a crucial transfer of electron density mediated by QEI from the Fe to the Co ions that maximizes the spin-moment in both metals. 


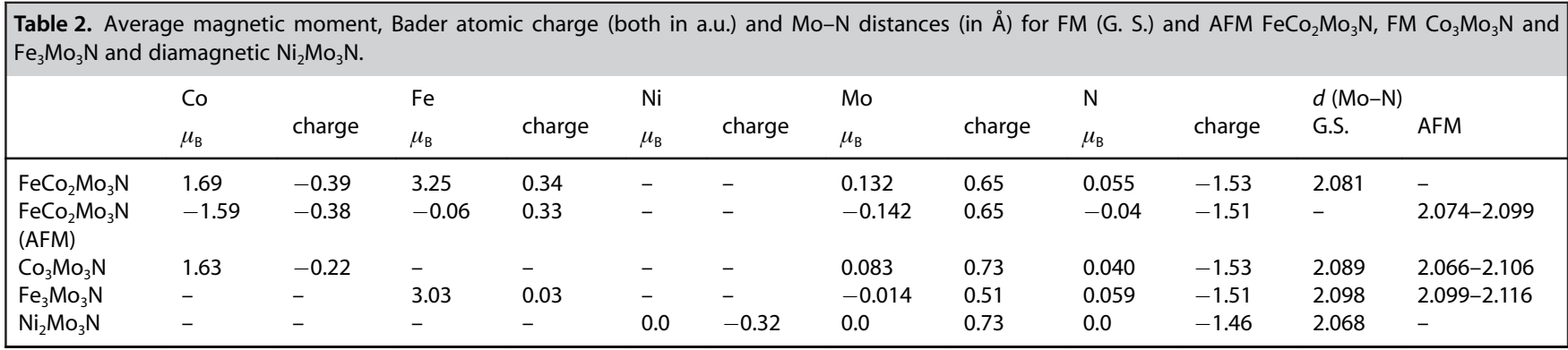

Overall, we observe that when moving from $\mathrm{Ni}_{2} \mathrm{Mo}_{3} \mathrm{~N}_{1-\delta}$ and $\mathrm{X}_{3} \mathrm{Mo}_{3} \mathrm{~N}_{1-\delta}(\mathrm{X}=\mathrm{Fe}, \mathrm{Co})$ to $\mathrm{FeCO}_{2} \mathrm{Mo}_{3} \mathrm{~N}_{1-\delta}$, there is an increase in the magnetic moment of all the metal atoms. As shown in Figure 2 and Table 2, the increasing magnetization of the Mo-N bonds shorten them, (non-classical) spin quantum mechanical effects of bonding, and spin-oscillations are easier, as $\mathrm{FeCO}_{2} \mathrm{Mo}_{3} \mathrm{~N}_{1-\delta}$ compositions have the smaller energy difference between FM and AFM phases. The relative electronic stability of the systems was perused by means of the relation: total

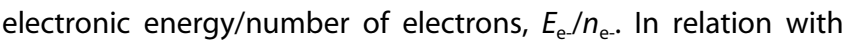
the Sabatier's principle, ${ }^{[35]}$ in a MvK mechanism the energy of formation of the $\mathrm{N}$-vacancies is in the middle zone for $\mathrm{FeCO}_{2} \mathrm{Mo}_{3} \mathrm{~N}_{1-\delta} ;$ in this respect, $\mathrm{Fe}_{3} \mathrm{Mo}_{3} \mathrm{~N}_{1-\delta}$ is too ionic, while $\mathrm{Co}_{3} \mathrm{Mo}_{3} \mathrm{~N}_{1-\delta}$ and $\mathrm{Ni}_{2} \mathrm{Mo}_{3} \mathrm{~N}_{1-\delta}$ interact with the ligands more weakly.

Ammonia synthesis is clearly less optimal for catalysts that do not present magnetic Mo-N bonds, which do not present FM QEI as part of the stabilizing forces in the orbitals. The magnetic structure seems one amongst many factors controlling catalytic activity; the best catalysts present increasing FM interactions at the active sites, and there is thus a connection between FM G.S., formation of vacancies and shorter Mo-N bonds.

We observe that the enhanced catalytic activity in FM $\mathrm{X}_{3} \mathrm{Mo}_{3} \mathrm{~N}_{1-\delta}$ compositions is due to similar electronic and magnetic factors as previously anticipated in strongly correlated oxides. ${ }^{[3]}$ The principles of spintro-catalysis seem to be valid and applicable to all catalysts including earth-abundant $3 d$-magnetic metals. In optimum catalysts for ammonia synthesis, there are spin polarized Mo-N bonds, where the minority spin is easier to extract from the partially occupied $A B$-orbitals and $Q E I$ facilitate nitrogen fixation, as the average distance between $A B$ electrons will be larger. The studied systems have no band-gap for any of the spins, what allows to maintain the total spin required for ammonia synthesis. Consequently, the increasing magnetic moment in shorter Mo-N bonds is a physically meaningful descriptor for the catalytic activity associated to FM spin-channels at the Fermi level. We propose again that the extra freedom provided by the QEI are effectively described by a Heisenberg Hamiltonian. Finally, we clarified that for these opening studies in relation with the influence of the spininteractions in catalysis, a deep study of the bulk properties is enough for obtaining predictive trends.

\section{Experimental Section}

All calculations were performed using periodic density functional theory (DFT) as implemented in the Vienna ab initio simulations package (VASP). ${ }^{[36-38]}$ The Projector Augmented Wave (PAW) method developed by Blochl was used to represent interactions between core and valence electrons. ${ }^{[39,40]}$ A plane wave cutoff of $400 \mathrm{eV}$ was used for all the elements, in conjunction with Monkhorst-Pack kpoint meshes of $11 \times 11 \times 11$. The Perde-Burke-Ernzerhof exchangecorrelation DFT functional revised for solids was used for all calculations. $^{[4]]}$ In order to properly describe on-site Coulomb interactions of localised $d$ electrons, DFT $+U$ methodology was used ${ }^{[42]}$ with values of $\mathrm{U}=2.0$ for $\mathrm{Co}$ and 4.0 for $\mathrm{Fe}$, as previously reported. ${ }^{[3,43]}$ Images were produced with VESTA. ${ }^{[44]}$

\section{Acknowledgements}

J.M. And V.P. Express their appreciation for the financial support from MINECO/FEDER project CTQ2015-67366-P and DGA/FSE (group E07). J.M. acknowledges the financial support provided by the Spanish "Ministerio de Educación Cultura y Deporte" (FPU14/ 06003). In addition, the resources from the supercomputer "memento", technical expertise and assistance provided by BIFIZCAM (Universidad de Zaragoza) are acknowledged. MagnetoCat $S L$ gratefully acknowledge significant funding from Syngaschem BV, Eindhoven (Netherlands), and Synfuels China Technology Co LTD, Beijing (China).

\section{Conflict of Interest}

The authors declare no conflict of interest.

Keywords: Ammonia synthesis - nitrogen fixation - Quantum Exchange Interactions · spin-dependent chemistry · Spintrocatalysis

[1] J. Gracia, Phys. Chem. Chem. Phys. 2017, 19, 20451-20456.

[2] R. Sharpe, T. Lim, Y. Jiao, J.W. H. Niemantsverdriet, J. Gracia, ChemCatChem 2016, 8, 3762-3768.

[3] J. Gracia, R. Sharpe, J. Munarriz, J. Catal. 2018, 361, 331-338.

[4] J. B. Goodenough, Rep. Prog. Phys. 2004, 67, 1915-1993.

[5] R. Sharpe, J. Munarriz, T. Lim, Y. Jiao, J. W. H. Niemantsverdriet, V. Polo, J. Gracia, Top. Catal., 2018, 61, 267-275.

[6] X.-L. Ma, J.-C. Liu, H. Xiao, J. Li, J. Am. Chem. Soc. 2018, 140, 46-49.

[7] S. Chu, A. Majumdar, Nature 2012, 488, 294-303.

[8] S. Mekhilef, R. Saidur, A. Safari, Renewable Sustainable Energy Rev. 2012, 16, 981-989. 
[9] A. Afif, N. Radenahmad, Q. Cheok, S. Shams, J. H. Kim, A. K. Azad, Renewable Sustainable Energy Rev. 2016, 60, 822-835.

[10] M. Appl, Ullmann's Encyclopedia of Industrial Chemistry, Wiley-VCH Weinheim, 2006

[11] T. Spatzal, M. Aksoyoglu, L. Zhang, S. L. A. Andrade, E. Schleicher, S. Weber, D. C. Rees, O. Einsle, Science 2011, 334, 940.

[12] K. M. Lancastrer, M. Roemelt, P. Ettenhuber, Y. Hu, M. W. Ribbe, F. Neese, U. Bergmann, S. DeBeer, Science 2011, 334, 974-977.

[13] C. J. M. van der Ham, M. T. M. Koper, D. G. H. Hetterscheid, Chem. Soc Rev. 2014, 43, 5183-5191.

[14] K. Arashiba, Y. Miyake, Y. Nishibayashi, Nat. Chem. 2011, 3, 120-125.

[15] J. S. Anderson, J. Rittle, J. C. Peters, Nature 2013, 501, 84-88.

[16] S. Kuriyama, K. Arashiba, K. Nakajima, Y. Matsuo, H. Tanaka, K. Ishii, K. Yashizawa, Y. Nishibayashi, Nat. Commun. 2016, 7, 1.

[17] C. J. H. Jacobsen, Chem. Commun. 2000, 12, 1057-1058

[18] N. Perret, A. -M. Alexander, S. M. Hunter, P. Chung, J. S. J. Hargreaves, R. F. Howe, M. A. Keane, M. A. Appl. Catal. A 2014, 488, 128-137.

[19] D. Mckay, J. S. J. Hargreaves, J. L. Rico, J. L. Rivera, X. -L. Sun, J. Solid State Chem. 2008, 181, 325-333.

[20] D. McKay, D. H. Gregory, J. S. J. Hargreaves, S. M. Hunter, X. Sun, Chem. Commun. 2007, 0, 3051-3053.

[21] C. D. Zeinalipour-Yazdi, J. S. J. Hargreaves, C. R. A. Catlow, J. Chem. Phys. 2016, 120, 21390-21398.

[22] S. M. Hunter, D. H. Gregory, J. S. J. Hargreaves, M. I. Richard, D. Duprez, N. A. Bion, ACS Catal. 2013, 3, 1719-1725.

[23] C. D. Zeinalipour-Yazdi, J. S. J. Hargreaves, C. R. A. Catlow, J. Chem. Phys 2018, 122, 6078-6082.

[24] J. Gracia, J. Munarriz, V. Polo, R. Sharpe, Y. Jiao, J. W. H. Niemantsverdriet, T. Lim, ChemCatChem 2017, 9, 3358-3363.

[25] J. T. Mefford, X. Rong, A. M. Abakumov, W. G. Hardin, S. Dai, Nat. Commun. 2016, 7, 11053.

[26] A. Zunger, Nat. Rev. Chem. 2018, 2, 0121.

[27] T. Waki, S. TerazawaY. Tabata, K. Sato, A. Kondo, K. Kindo, H. Nakamura, Phys. Rev. B 2014, 90, 014416.
[28] L. A. Sviridov, P. D. Battle, F. Grandjean, G. J. Long, T. J. Prior, Inorg. Chem. 2010, 49, 1133-1143.

[29] E. Haque, A. Hossain, J. Alloys Compd. 2018, 748, 117-126.

[30] K. S. Weil, P. N. Kumta, J. Grins, J. Solid State Chem. 1999, 146, 22-35.

[31] Y. Z. Jiao, R. Sharpe, T. Lim, J. W. H. Niemantsverdriet, J. Gracia, J. Am. Chem. Soc. 2017, 139, 16604-16608.

[32] S. K. Jackson, R. C. Layland, H. C. zur Loye, J. Alloys Compd. 1999, 291 94-101.

[33] S. Alconchel, F. Sapina, D. Beltran, A. Beltran, J. Mater. Chem. 1998, 8 1901-1909.

[34] R. L. McNaughton, J. M. Chin, W. W. Weare, R. R. Schrock, B. M. Hoffman, J. Am. Chem. Soc. 2007, 129, 3480-3481.

[35] A. J. Medford, A. Vojvodic, J. S. Hummelshøj, J. Voss, F.-A. Pedersen, F. Studt, T. Bligaard, A. Nilsson, J. K. Nørskovz J. Catal. 2015, 328, 36-42.

[36] G. Kresse, J. Hafner, Phys. Rev. B 1993, 47, 558-561.

[37] G. Kresse, J. Hafner, Phys. Rev. B 1994, 49, 14251-14269.

[38] G. Kresse, J. Furthmüller, Phys. Rev. B 1996, 54, 11169-11186.

[39] P. E. Blöchl, Phys. Rev. B 1994, 50, 17953-17979.

[40] G. Kresse, D. Joubert, Phys. Rev. B 1999, 59, 1758-1775.

[41] J. P. Perdew, A. Ruzsinsky, G. I. Csonka, O. A. Vydrov, G. E. Scuseria, L. A Constantin, X. Zhou, K. Burke, Phys. Rev. Lett. 2008, 100, 136406.

[42] S. L. Dudarev, G. A. Botton, S. Y. Savrasov, C. J. Humphreys, A. P. Sutton, Phys. Rev. B 1998, 57, 1505-1509.

[43] M. Aykol, S. Kim, C. Wolverton, J. Chem. Phys. 2015, 119, 19053-1908.

[44] K. Momma, F. Izumi, J. Appl. Crystallogr. 2011, 44, 1272-1276.

Manuscript received: July 3, 2018

Accepted Article published: August 23, 2018

Version of record online: August 23, 2018 


\section{COMMUNICATIONS}

Enhanced ammonia synthesis in ferromagnetic nitrides is shown to correlate with increasing ferromagnetism in the metal-nitrogen bonds, which constitute the active sites. Indeed, the total spin accumulated in the Mo-N bonds at the active sites indicates optimum catalytic activity.

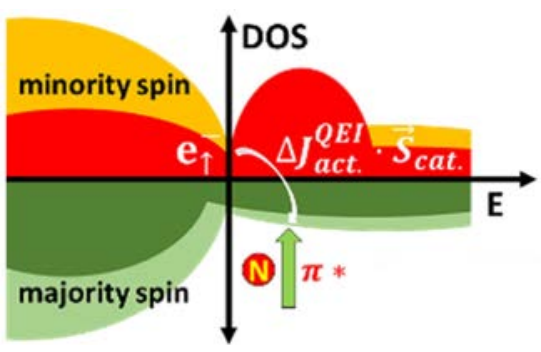

J. Munarriz*, Dr. V. Polo, Dr. J. Gracia*

$1-6$

On the Role of Ferromagnetic Interactions in Highly Active Mo-Based Catalysts for Ammonia Synthesis 